\title{
Alcohol-based hand rubs must meet the requirements of EN 1500
}

\author{
Sven Eggerstedt PhD, Patricia Fliß PhD, Erika Mönch PhD and Christiane Ostermeyer \\ Bode Chemie GmbH, Hamburg, Hamburg, Germany
}

To the Editor-Kramer et al conducted an interesting study to compare the outcome of different application times (15 seconds and 30 seconds) for hygienic hand disinfection under practical conditions in which they were able to show a significant increase in frequency of hand rub actions when the recommended application time was reduced from 30 seconds to 15 seconds. Although the authors clearly state that only alcohol-based hand rubs (ABHRs) that meet the requirements of the EN 1500 in $15 \mathrm{sec}-$ onds are suited to be applied with a shortened application time of 15 seconds under practical working conditions, the published results for the different ABHRs do not demonstrate a sufficient efficacy in 15 seconds according to EN 1500.

Methods like EN 1500 (phase 2, step 2) offer a standardized procedure to compare the in vivo efficacy of ABHRs under laboratory conditions, and they function as an important criterium in the authorization process of these products independently if they are regulated as medicinal or biocidal products. The EN 1500 procedure specifies how ABHRs must be tested in comparison to a defined reference procedure $(2 \times 30$ seconds; $2 \times 3 \mathrm{~mL}$ $60 \% \mathrm{v} / \mathrm{v} 2$-propanol), and it provides statistical requirements that must be fulfilled by the test products. Furthermore, EN 1500 allows the testing of ABHRs only with durations between 30 seconds and 60 seconds. Notably, application times shorter than 30 seconds are not authorized. To obtain meaningful conclusions out of the test results, it is essential that the tests are conducted exactly the way they are described in EN 1500.

Kramer et $\mathrm{al}^{1}$ tested various products covering a broad range of alcohol content following a modified EN 1500 (1997) method. ${ }^{1}$ In other words, the test parameters defined in the European Norm were altered in these tests. In addition, an outdated version of the method, which was revised in $2013,{ }^{2}$ was applied, and Kramer et al also modified the reference procedure significantly without providing an explanation for this approach. Compared to EN 1500, in their study, the application volume of the refence alcohol $60 \% \mathrm{v} / \mathrm{v}$ 2-propanol was halved from 6 to $3 \mathrm{~mL}$, and the application time was reduced from 60 seconds to 30 seconds.

Rotter et $\mathrm{al}^{3}{ }^{3}$ who investigated the impact of variations in the standard procedure of EN 1500, showed that the shortened duration of the reference procedure (15 seconds or 30 seconds instead of 60 seconds) in combination with half the disinfectant volume $(1 \times 3 \mathrm{~mL}$ instead of $2 \times 3 \mathrm{~mL})$ led to a reduction in the bactericidal efficacy of 2 -propanol on the hands. ${ }^{3}$ In their tests, the differences were significant between 30 seconds with $3 \mathrm{~mL}$ and 60 seconds with $2 \times 3 \mathrm{~mL}$ as well as between 15 seconds with $3 \mathrm{~mL}$ and 60 seconds with $2 \times 3 \mathrm{~mL}$.

Considering these results, the hurdle to success in one of the most stringent standard testing norms, as it was called by
Kramer et al, was dramatically lower in their ABHRs in vivo tests following EN 1500. In fact, however, their test design did not follow the EN 1500 method. Therefore, Kramer et al's conclusion that all tested ABHRs fulfilled EN 1500 in 15 seconds is misleading. Readers should be aware that ABHRs consisting of ethanol in the range of $70 \% \mathrm{w} / \mathrm{w}(75 \% \mathrm{v} / \mathrm{v})$, for example, which were also tested by Kramer et al, did not fulfill the EN 1500 requirement in 30 seconds with $3 \mathrm{~mL}$ in other studies. ${ }^{4,5}$ Therefore, it is highly improbable that those products will be effective in 15 seconds if tested according to the EN 1500 method with an application volume of $3 \mathrm{~mL}$.

We would also like to address the efficacy findings under practical working conditions. Kramer et al observed no significant efficacy differences between the groups rubbing hands for 15 seconds and 30 seconds. This finding is not surprising because in both groups nearly the same amount of ABHRs $(3.4 \mathrm{~mL}$ vs $3.3 \mathrm{~mL}$ ) was applied. Furthermore, "there was no difference in duration for hand antisepsis action between both groups," as Kramer et al state in the discussion section of their publication.

In conclusion, we strongly support all efforts to improve hand hygiene compliance in clinical practice. However, the efficacy of ABHRs should be proven according to established test methods (ie, EN 1500) without modifications that lower their requirements.

Financial support. No financial support was provided relevant to this article.

Potential conflicts of interest. All authors are employees of Bode Chemie GmbH.

\section{References}

1. EN 1500. Chemical disinfectants and antiseptics. Hygienic hand rub. Test method and requirements (phase 2/step 2). Brussels: European Committee for Standardization; 1997.

2. EN 1500. Chemical disinfectants and antiseptics. Hygienic hand rub. Test method and requirements (phase 2/step 2). Brussels: European Committee for Standardization; 2013.

3. Rotter ML, Suchomel M, Weinlich M, Kundi M. Impact of shortening the duration of application and the standardized rubbing sequence as well as the reduction of the disinfectant volume used for the hygienic hand rub with 2-propanol (60 \% v/v). Hyg Med 2009;34:19-23.

4. Suchomel M, Kundi M, Pittet D, Weinlich M, Rotter ML. Testing of the World Health Organization recommended formulations in their application as hygienic hand rubs and proposals for increased efficacy. Am J Infect Control 2012;40:328-331.

5. Kampf G, Ostermeyer C, Werner HP, Suchomel M. Efficacy of hand rubs with a low alcohol concentration listed as effective by a national hospital hygiene society in Europe. Antimicrob Resist Infect Control 2013;2:19-25.
Author for correspondence: Sven Eggerstedt, Bode Chemie GmbH, Melanchthonstr. 27, 22525 Hamburg, Germany. E-mail:sven.eggerstedt@bode-chemie.de

Cite this article: Eggerstedt S, et al. (2018). Alcohol-based hand rubs must meet the requirements of EN 1500. Infection Control \& Hospital Epidemiology 2018, 39, 1018. doi: 10.1017/ice.2018.129

(c) 2018 by The Society for Healthcare Epidemiology of America. All rights reserved. 